\title{
Fallopian Tube Adenomatoid Tumor
}

National Cancer Institute

\section{Source}

National Cancer Institute. Fallopian Tube Adenomatoid Tumor. NCI Thesaurus. Code C40129.

A benign neoplasm that arises from the fallopian tube and originates from mesothelial cells. It is characterized by the presence of gland-like structures that are lined by flat or cuboidal cells. It is usually discovered as an incidental finding. 